\title{
A Problem for Environmental Pragmatism: Value Pluralism and the Sustainability Principle
}

\author{
Okke Loman \\ Institute for Philosophy, Universiteit Leiden, Leiden, Netherlands \\ ooloman@gmail.com
}

\begin{abstract}
In this article, I suggest that the recently emerged perspective of environmental pragmatism encompasses self-contradicting principles. For many years, it was deemed impossible for environmental ethics to formulate justified environmental policy. Environmental pragmatism, and its primary scholar Bryan G. Norton, has promoted a new outlook in that debate by proposing an ideal methodology based upon classic American pragmatism. In this methodology, a community can determine what is morally righteous by (i) conducting open-ended inquiry and (ii) considering all relevant stakeholders in a rational discourse. Environmental pragmatism must therefore accommodate reasonable value pluralism. Moreover, Norton claims that these criteria should be complemented with what I call the 'sustainability criterion'. However, this principle of righteous decision- making appears inconsistent with the two aforementioned commitments. This article considers why this is the case.
\end{abstract}

\section{Keywords}

environmental ethics - environmental pragmatism - epistemology - sustainability deliberation - Bryan G. Norton

\section{Introduction - the Challenge of Environmental Policy}

Traditionally speaking, theories of ethics - developed and brought forward by notables such as Aristotle, Immanuel Kant and John Stuart Mill - commonly enunciate certain aspects that make our actions and characters morally wrong, virtuous or vicious. When the field of environmental ethics emerged, it was 
claimed that this view was incomplete. More particularly, these traditional theories were said to be too anthropocentric - the belief that only human beings possess moral value. The stage was thus set to develop the field along non-anthropocentric lines, in which it was indeed claimed that intrinsic value should be attributed to nature. ${ }^{1}$ That is, valuing nature as an end in itself, regardless of whether that nature can be used for something else, more specifically so for the benefit of mankind. ${ }^{2}$ Ever since, the field of environmental ethics has experienced growth, with a broad range of dividing lines in it. Without elaborating upon these disputes, it can be stated that they are all drawn from the struggle of whether or not, or to what extent, we should value nature for its own sake or for the advantage of human beings.

Recently, the field of environmental ethics has experienced a 'pragmatic turn' (Stephens 2007; Minteer 2011, 7-12). In the 1980s, Anthony Weston had already offered a new possibility for environmental ethics to adopt a more pragmatic, action-based attitude (1985). It was, however, an influential anthology of papers assembled by Andrew Light and Eric Katz in the 199os that led to the now significant academic perspective of so-called environmental pragmatism (which I refer to hereafter as 'EP') (1996). 'Pragmatic' should here not be regarded as the everyday meaning referring to the focus on achieving only practical results. Rather, in the philosophical discourse, as mentioned here, pragmatism in environmental ethics is founded upon the commitments of American pragmatism - most notably brought forward by Charles Peirce, William James and John Dewey. This interpretation of pragmatism is widely known for its efforts to make philosophical analysis relevant to urgent ethical, social and political questions and has served as the primary influence on the pragmatic shift in environmental philosophy.

Just as American pragmatism focussed on everyday problem-solving, EP aims at doing the same. ${ }^{3}$ Rather than debating intrinsic value, EP wants to offer an alternative: we should immediately seek solutions that work and are acceptable for all involved (Odenbaugh 2012; Minteer 2017). ${ }^{4}$ Crucial in this

1 Among others, the most prominent non-anthropocentric scholars include: Richard Routley, Holmes Rolston, Kenneth Goodpaster, Paul Taylor, Laura Westra, Eric Katz, and J. Baird Callicott.

2 Complementary, something is of instrumental value when the value of that something comes from the means for an end of something else.

3 Although American pragmatism is a wide tradition, Hilary Putnam famously identified four main characteristics of pragmatism upon which I will return: the refusal of skepticism; the readiness to espouse fallibilism; a holistic approach of sharp dichotomies like fact and value, and 'primacy of practice' (Putnam 1994).

4 EP includes a broad range of particular views, but the features mentioned in this thesis are commonly accepted in any interpretation of EP (Light and Katz 1996; Norton 2007a; Stephens 
understanding is not only the acceptance, but more importantly, the accommodation of value pluralism in society. Just as in the American tradition, EP rejects epistemic foundationalism, or the denial of the notion that knowledge and belief are grounded in some sort of certain, fixed class or principle and that basic beliefs thereby do not require any justification. Therefore, EP embraces an experimental and fallibilistic view of knowledge, including moral knowledge, that also entails a pluralistic rather than a singular view of belief and values, since a multitude of views increases nuance and potential right answers. ${ }^{5}$ So, how can we then know what a righteous solution to certain (environmental) problem entails? Environmental pragmatism claims that truth, and the morally righteous route, will emerge from the dynamic method of discussion, debate and the open exchange of views, arguments and persuasion in the community. We come to know what is right because we continuously and consciously consider a plurality of values by means of deliberation, discussion and open debate. And so, if all sides - including those that echo the interests of both nature and human beings - are considered equally, we can formulate proper solutions for our urgent environmental problems. Value pluralism is thereby not only considered; it is the core of getting to knowledge (Norton 2015, 286).

However, EP seems to face a prima facie problem, which emerges from a prime difference between classical pragmatism and EP. As EP wants to include a variety of values in the debate, it does so with a certain aim: the aim of sustainability. Within EP, any righteous policy should include 'the transition to a more sustainable society' (Minteer 2008, 181; Norton and Minteer 2002, 374). So, what is a sustainable society? Bryan Norton, EP s most prominent and influential scholar, has defined the criterion of sustainability as follows: 'A set of behaviors (an institution, a policy, or a management practice) is sustainable if and only if its practice in generation $\mathrm{m}$ will not reduce the ratio of opportunities to constraints that will be encountered by individuals in generations $\mathrm{n}$, o, p...' (2009, 41). As I have just outlined, EP does not adopt any fixed principles as a foundation. Yet, the aim of sustainability seems to be precisely such a fixed foundation. In fact, Norton holds this aim as a guiding principle for any

2007; Minteer 2008; Minteer 2011; Sarkar and Minteer 2018). Please see Vik (2014) as to how EP has become such an influential position in environmental philosophy.

5 This does not mean, however, that the pragmatist is downright skeptical. As opposed to the absolute skeptic, the pragmatist can hold beliefs, as long as she is open to the fact that she cannot attain absolute certainty concerning questions of fact - even if such beliefs have good reason to hold based upon previous experience. This is meant by fallibilism, as Peirce defined it (1955). Hilary Putnam has suggested that the insight that antiskepticism and fallibilism can go together could be the most original epistemological observation of pragmatism (1995). 
justified decision, which means that an unsustainable outlook or value would be impermissible (Norton 2005; 2015). But this would contradict the original commitment EP, which was to integrate any value.

In this paper, I suggest that the principles of EP are indeed self-contradicting, which seems to make EP become nonviable on its own terms. I make my suggestion by considering the epistemological assumptions of EP, and its derived principles. Moreover, I shall make my claims on the basis of Norton's work. ${ }^{6}$ In the second section of this paper, I further introduce Norton's philosophy. I will then unearth the epistemological commitments made by EP in the third section - and how these relate to classical pragmatism. On the basis of these commitments, Norton prescribes three principles for ideal deliberation, or the procedure for coming to justified policy. I address in the fourth section the open-ended inquiry principle and in the fifth section the discourse principle. I subsequently regard how EP relates to environmental decision-making, by first considering the general concept of sustainability (section six) and Norton's view on it (section seven). Lastly, in section eight, I introduce Norton's third principle for EP, the sustainability criterion. It is here where EP s contradictory tendency comes to light. I conclude with the invitation to EP to resolve its seemingly self-contradicting principles.

Before I argue for my claim, I must present two small remarks. First, I fully acknowledge that this theoretical problem-solving practice seems to defy EP in itself. Surely, EP prescribes that we should not theorise about environmental issues in the manner I do in this paper. But, for EP to offer a coherent alternative in environmental ethics, it must resolve this prima facie problem. After all, it would be even less appropriate to simply apply a pragmatic maxim to any environmental decision for no clearly justified reason at all. We ought to have good reasons for embracing EP. Second, I present a remark about what this paper aims to clarify. Only very recently has EP been considered a meaningful alternative in the environmental debate. And although considerable critiques have been written about the approach, it still contains many ignored aspects. ${ }^{7}$

6 Norton's influence has been underlined last year, when an extensive monograph was published his philosophy (Sarkar and Minteer 2018). This paper can be seen as a response to that collection of work. I am fully aware that Norton does not represent all of EP s scholars. But because of his influence, this paper should be an addition to EP s literature in general. To be as clear as possible: when I refer to EP, I mean Norton's view of EP.

7 The main points of critique can be captured into five main problems. The three most spread are (a) economism; (b) reductionism and (c) subjectivism (Stephens 2012). Moreover, some philosophers have argued that (d) EP is no philosophical position at all (Samuelsson 2010), and is (e) unable to apply its methodology to the global sphere of environmental problems (Brister 2018). 
One of these features is the here-mentioned association between deliberation and sustainability. This paper, though, has a constructive aim. By considering the criticism, I hope to illuminate a potential key problem EP faces. Although I myself do not make an effort in this paper to solve the problem, I hope that by critically assessing EP, others will be able to further strengthen EP s philosophy. And by doing so, to further advance proposals for addressing environmental issues.

\section{$2 \quad$ Norton's Pragmatic Decision-Making}

Of all scholars in EP, Bryan G. Norton has most notably advocated a framework to diffuse the pressure on the challenge of environmental policy and to guide action for morally righteous policy. ${ }^{8}$ Norton is convinced that the dualism of anthropocentric values and non-anthropocentric values is false. By reducing environmental disagreements to merely a black and white (human/non-human) discussion, we lose sight of the actual positions of continually developing views. Instead, Norton claims, such dichotomies should be replaced by a broad spectrum of values varying from small and short-term to long-lasting: 'Pragmatists believe that dichotomies and dualisms usually stand in for disguised continua and are best avoided - dissolved - when possible' $(2005,507)$. For instance, it could be possible to value both human beings and the ecosystem, or the human/animal relationship as well. This assumption of a variety of values can be traced back to John Rawls' definition of 'reasonable pluralism'. He stated that 'there is no single comprehensive philosophical, religious or moral doctrine upon which reason converges' (Rawls 2005, 36; Aikin and Talisse 2018, chapter 10). In other words, reasonable people - individuals that are intelligent, sincere and honest, who do their epistemic best by carefully considering the right questions - will nonetheless differ in their answers about the Big Questions, such as 'What is morality?' or 'What is the good life?' And so, according to Norton, we should acknowledge value pluralism in society and bring these insights and views together in deliberation that can reasonably assess these views.

Given this observation, the question that I now raise is how Norton's EP wishes to guide action for policy. As I explain, Norton's framework is an ideal

8 He calls this framework 'adaptive ecosystem management' (1999a; 2005; 2015). In this paper, though, I will keep referring to Norton's theory as 'Norton's EP'. This is because I mainly address the epistemological commitments in his theory and the appearing contradiction these have with the aim of his theory. 
procedural account of policy making. This ideal has been subject to extensive analysis, but it is my interpretation that it consists of two primary principles for coming to know what the right policy is. I therefore refer to these commitments as EP s 'epistemological principles', which are (i) the open-ended inquiry principle and (ii) the discourse principle. ${ }^{9}$ I address both principles below. When the epistemological principles are met in the procedure of decision-making, a community can be confident that the right and justified decision is reached. As I indicate, the procedure to which these principles are applied is a deliberative process. And as I unearth, ideal deliberation is only possible when the community not only acknowledges but also accommodates reasonable value pluralism. As Norton states, 'pluralists encourage and expect to learn from a diversity of opinion; pluralism and free expression contribute to truth-seeking' $(2015,113)$.

But, before I address the procedural ideal of policymaking, I should unearth the epistemological assumptions of EP, because two main questions now appear: (a) Before the compromises between different values that are proposed by Norton can be found, he wants to let in and consider any possible value. But, if any value should be considered, because the cross-pollination of these values is what brings truth forth, what should we then do with facts? It seems that facts are then nothing more than another option in the process of choosing what is a right value. (b) And, how should we regard a plurality of values (i.e. should any primacy be given to some values, or some facts)? This method is epistemological in its very essence: it revolves around the question of how we can know what the righteous decision, or righteous policy, is. As I note, both principles are preceded by two epistemological assumptions that emerge from classical American pragmatism. The first is the holistic avoidance of the fact-value dichotomy; the second is the commitment of practice over principle. Norton explicitly references classical pragmatism in both regards. ${ }^{10}$ So, let us now first consider the influence of classical pragmatism on EP.

9 These principles are derived from Norton's set of 'procedural heuristics'. These are criteria to promote decision-making in the context of value pluralism and epistemic uncertainty. I have taken the liberty to re-classify Norton's heuristics into the above mentioned principles. Principle (i) adheres to Norton's second 'epistemological heuristic', principle (ii) is seen back in Norton's 'process rationality heuristic' $(2015,293)$. Norton further uses this last consideration to equate 'appropriate' with 'rational'. I will later return on this. There are two more heuristics upon which I reflect in Section 7 , and which are seen back in Norton's sustainability principle.

10 He specifically does so in the appendix of his magnus opus Sustainability: A Philosophy of Adaptive Ecosystem Management, in which he claims his epistemological method is an extension of the ideas of Dewey and Peirce (Norton 2005). 
In many ways, American pragmatism can be considered a tradition occupied with questions of knowledge. As this movement flourished in the late 189 os and early 19oos, most famously put forward by contemporaries Charles Sanders Peirce, William James and John Dewey, it argued that knowledge is only obtainable when coupled with action (Haack 2004; Bragg 2005; Putnam and Putnam 2017). We can only know by doing. Hence, pragmatism has the 'pragmatic' in the name. ${ }^{11}$ Pragmatism was a reaction to the prevailing absolutist metaphysics of Truthness and Falseness, which claimed that there is one external, objective truth that serves as an epistemological foundation.

Pragmatism claimed that this idea of a foundational, fixed set of Truth(s) and thus beliefs and facts should be refuted (Bacon 2012, 2-7). By doing so, the pragmatists reinterpreted the meta-theory of propositions for knowledge. As mentioned above, it was traditionally claimed that propositions of knowledge possessed this fixed bias: something is absolutely amenable via empirical verification. However, the pragmatists claimed, verification theories are in themselves inescapably reliant on background assumptions (Anderson, 1998). This makes the prepositions presuppose value judgements with which, then, states of affairs are described. This led Dewey to note that a proposition should be interpreted as a suggestion that is animated by values - including a truth proposition. It is therefore necessary to be aware that there are values thus underlying factual assumptions. Because science is occupied by the determination of facts, and facts are not value free, the scientific discourses are also value laden.

Norton draws heavily upon these insights for his EP. He claims that the statue of science as an impartial provider of facts no longer holds (2005, §10.3). This means that science can thereby no longer guide actions or inform policy on the justification of Absolute knowledge, precisely because scientific claims are informed by values in themselves, as well. Particularly with very complex problems in which not only are scientific uncertainties present but clear values and interests also play a significant role. For instance, regarding mankind's infringement on the environment, if we only wish to follow the facts, we will miss that (a) facts are also value laden and (b) clear values may also play a role in action guidance. And so, the dichotomy of facts and values is then surpassed (Norton 1999a).

Consequently, the question emerges: is there no difference at all between facts and values? Norton seems to suggest as much: if values are what

11 I would like to underline that pragmatism should not be regarded as a coherent movement. That would hide the fact that its leading figures had major disagreements. 
informs the scientific community - which is responsible for bringing forth scientific facts - then it seems that these scientific facts are nothing more than echoes of certain values. Regardless, Norton rejects this. And, as he does more often, Norton reflects back on American pragmatism to elaborate why scientific facts, though value laden, are not the same as values (1999a). What is at stake here is the question of why a scientific fact is more developed towards knowledge than a value that forms the background of that fact.

The fallibilism of Peirce should be considered in this context. Peirce claimed that we can develop methods in approximating to know things in themselves, but we can never entirely know a thing 'in itself'. And, the right method is the scientific method, on the basis of induction, deduction and abduction - in short, of competent inquiry. Hence, Peirce stated that 'truth can be nothing more nor less than the last result to which the following out of this [experimental] method would ultimately carry us' (Nesher 2002, 70). And so, although fact and value should not be considered a dualism, the pragmatists did regard a fact as a 'developed' type of description. The method of that development, they called 'inquiry' (Norton 2015, 11).

Dewey advanced this notion of inquiry upon which Norton builds. It is important to note that inquiry, to Dewey, always occurs in a community, and it begins with a practical problem that one wants to solve. He named such a problematic scenario an 'indeterminate situation' (Dewey 1938, 108). And inquiry is, to Dewey, 'the controlled or directed transformation of an indeterminate situation into one that is so determinate in its constituent distinctions and relations as to convert the elements of the original situation into a unified whole' (Dewey 1938, 171). The situation is thereby fixed: it is transformed into a new situation that can reasonably explain our observations. The solution is always only possible through examination and experience, by setting up hypotheses and investigating if these succeed: if one finds a practical solution, the problem is evidently solved and thus becomes determinate. This is true for problems in the scientific world as well as for moral and ethical problems, to which I return later.

If a problem is solved by the community and has become determinate, the hypothesis is then one of 'warranted assertability' (Dewey 1938, 15). The claim, or hypothesis, is defensible - asserted - by the force of reason and so the claim is justified, or warranted. Like Peirce, Dewey claimed that by means of inquiry, we can approximate the truth and ameliorate our descriptions of the world around us. And so, Dewey meant that 'truth is internal to inquiry' (Tiercelin 2014, chapter 1). He thus related truth to what is useful to believe (Dewey 1941). It is crucial to indicate that although Dewey noted that truth is 
'the opinion which is fated to be ultimately agreed to by all who investigate', he did not equal truth with the outcome of inquiry (i.e. warranted assertibility). This is because he was against the notion that truth is some fixed state (Dewey 1938, 268). Instead, Dewey noted that truth relates to hypotheses, which are subsequently set up as future claims, ready to be tested and altered if needed (Dewey and Sleeper 1988, 56-7).

By applying the term warranted assertibility, Dewey favoured the process of coming to know what is right (Bacon 2012, 56). By continuous inquiry are we able to constantly improve our descriptions, yet we are not able to correspond to the external state of affairs. Knowledge is thus the output of competent inquiry and subsequent decision-making is a process of determining what works. In summary, the pragmatists claimed that we only hold something to be true (i.e. warranted assertibility). Because of competent inquiry, we have a justification to hold that claim as the truth, until someone provides better reasons to hold something else as true.

So, does this open the door to the problematic viewpoint of (moral) relativism, in which (moral) judgements are only true or false relative to a cultural standpoint that can differ based on time and place? On the basis of Dewey and Peirce, Norton says that it does not, by reason of the aforementioned competent inquiry (Hirsch 2018, 89). As I stated above, a process of inquiry can be dubbed 'competent' if it follows the scientific method. This methodology of rational, and logical, deduction, induction or abduction plays a vital role here. Peirce and Dewey previously noted that inquiry is the general practice of science - that is, of all sciences. As I mentioned above, science is shaped by values in the community, but these are values that are reflective of the manner in which questions, methods and acknowledged opinions are upheld. It is for this reason that Dewey - and Norton after him - credited science with such a crucial role in inquiry: science's inquiry makes it self-conscious of the values that shape its discourse. And, because of the scientific methodology, values are developed into warranted assertions. This dismisses Norton of (moral) relativism, because he claims that we can get better at knowing what is right. And so, we can recognise the superiority of a certain utterance over the other because of experience, experimentation and rational dialogue. The pragmatist continues: as scientific inquiry makes us move towards warranted assertions and thereby to what we can hold as true, the same holds for moral inquiry (Anderson 1998). We can determine what is right and wrong by abandoning long-lasting fixed principles that could form hurdles in solving actual problems. Hence, we should hold practice (experimenting, inquiring) over principle (assuming any fixed foundation). 
It should now be clear that the best possible claim to truth (a warranted assertion) is only possible by continuously bringing forward a plurality of values that allows us to experiment with different perspectives to determine which works best. And so, different communities might legitimately prioritise or follow different values, because indeed, more than one acceptable set of values exists. According to Norton, it is then the role of ethicists and policymakers to facilitate the process of inquiry through which these different values are subsequently assessed and to formulate solutions. The ambition, of course, remains pragmatic: not to formulate universal moral truths for their own sake but to transform problematic situations into more workable ones for all stakeholders. It is, as I have mentioned previously, in such a case, not necessary to agree upon fundamental values, as long as the outcome is agreed upon. Therefore, for Norton, the focus of environmental policymaking is to define a public participation methodology in which stakeholders are occupied with joint inquiry to reach a cooperative solution, instead of discussing value systems as such (Brister 2018).

Because of his insight that scientific facts are also informed by background values, Norton argues that 'to include not just scientists from established disciplines, but also parties, stakeholders who have varied interests and viewpoints and who express their viewpoints in an open and public process' $(2005,115)$. In short, he claims that because values are always informing the scientific community, this affects the outcomes of 'scientific facts'. And, because a multitude of values exist in a multitude of scientific communities, we should be open to various ways of knowing - therefore, value pluralism should be facilitated (Thompson 2007; 2018). Indeed, this value pluralism is essential for knowledge, as the more values are considered, the more possible answers are brought forth. Open-ended inquiry will then make us bring in these answers. Therefore, we should commit to endlessly attempting to formulate better solutions in the process - that way are we able to get to better solutions. This is what I call the open-ended inquiry principle. ${ }^{12}$

Norton follows Dewey by placing inquiry - and thus experimentation - at the heart of environmental decision-making (Norton and Steinemann 2001, 479). Policymaking is thus a process of learning about the world, or about determining the best course of action for the public interest; by means of inquiry, we can collect and gather experience and thus possible knowledge in the community. Inquiry is self-corrective if applied and submitted in an

12 To be as precise as possible: Norton himself does not explicitly uses the term 'open-ended principle'. He rather suggests continuous 'experimentation' (Norton 2015, 57). I do believe, however, that my term captures his views. 
open community in which claims can be tested to clarify, justify, refine and debunk proposed truths - we are thus able to progress in our understanding of the world. As Norton himself states, 'communities can learn and grow with respect to their values, modifying their goals en route, as well as use scientific and technical means to improve their understanding of system behavior. The incremental learning strategy also reacts to problems with experiments and actions' $(2015,11)$. In the next section, I examine how this modification occurs. For now, the open-ended inquiry principle is the first epistemological commitment for the procedure to formulate righteous policy.

\section{The Discourse Principle}

By means of open-ended inquiry, the community continuously considers as many views as possible. And, therefore, we must accommodate value pluralism, because value pluralism offers the community as many possible answers as possible. The question that now arises is how are we able to assess those choices - to ensure that the community makes the best choice for a possible policy? It is here that Norton complements his open-ended inquiry in the ideal procedure for decision-making.

To answer this question, Norton draws heavily upon Jürgen Habermas' procedural approach, based on the 'discourse principle' (Norton 2007a, 14-15). This principle states that only the norms that can claim validity are those upon which all potentially involved persons can agree as participants in rational discourses (Keulartz 2018, 197). Now, what is considered to be a rational discourse, according to Habermas, is one that ensures that the outcomes of the discourse are concluded by no other force than that of the better argument. This can be done if and only if the discourse meets the subsequent conditions: '(a) that nobody who could make a relevant contribution may be excluded; (b) that all participants are granted an equal opportunity to make contributions; (c) that the participants must mean what they say; and (d) that communication must be freed from external and internal coercion' (Habermas 1998, 44). And so, the solutions brought forward by the community must be aligned with procedural norms that promote fairness, openness, inclusiveness and mutual respect among the members of the community (Keulartz 2018, 190).

Norton would always opt for 'the more (values) the merrier', because in such a case, a new perspective can shed new light on the problem. Even if we have settled on an issue, new views should continuously be explored (which is seen back in the open-ended inquiry principle). And, if such a new perspective, or value, is unreasonable, it will turn out - due to the discourse principle - to be unreasonable 
and thus be rejected. So, when such a broad spectrum of values is acknowledged, we can, by means of reasonable deliberation, arrive at agreeable terms for all stakeholders. By considering everyone, we can work towards practical solutions upon which all stakeholders in the community agree. ${ }^{13}$ In practice, this means that the community proposes as many views as possible - open-ended inquiry - before the views are assessed on the basis of the discourse principle. Any participant can, of course, propose any new consideration. Thus, the two principles are reciprocal. They continuously reinforce each other to create better solutions (i.e. knowledge). Hence, the metaethical disagreements over the source of value dissolve in the situation of practical policy formulation. There is no longer a need to dispute which values should be considered most important, because in Norton's case, all stakeholders involved will be satisfied. We can thus point towards workable compromises. This makes Norton's EP a procedural political system, in which its contributors specify relevant values, discuss them and settle disputes.

Now, it could be argued that Norton's manner of prescribing truth finding is the foundation of EP. But, EP would then be self-contradictory, because it has vowed to reject any form of foundationalism. Also, EP claims that strictly speaking, any principle should be rejected, yet it claims that deliberation should be based upon the 'discourse principle. What do we think of this? Both arguments can be refuted by noting that neither involve matters of truth: EP rigorously rejects a foundation for knowledge but does in fact acknowledge a foundation for the methodology to obtain knowledge. These principles and foundations are the procedures; they are not substantive principles or foundations of truth itself. But, even then, it could be argued that EP knows that the methodology of knowledge is right because of a foundation of knowledge. And so, it appears that EP still holds on to an epistemological foundation. However, this argument can be nullified by noting that EP actually does not in fact claim that it possesses Absolute certainty over that epistemological foundation (of the methodology). Instead, according to their own principle, EP has only warranted assertibility that this foundation is momentarily the most righteous.

Sustainability in General

At this moment, it is clear how Norton draws on the epistemological commitments of classical pragmatism to structurise a procedural methodology

13 I will simply assume that 'community' means a group of people that are conditioned by a certain shared attitude, value or interest. Questions, of course, can be raised here. For part of that critique see Wolf (2018). 
for decision-making. It is, however, not yet clear how this could be of any righteous use in environmental policymaking. Now that I have examined the 'pragmatism' in Norton's EP, I delve deeper into the 'environmental' side of the practice. Crucial in this regard is Norton's notion of 'sustainability'. Indeed, for the last 25 years, Norton has devoted his work entirely this theme. To understand Norton's view of sustainability, it is first necessary to analyse the general notion of sustainability in greater depth and, subsequently, how it is applied to Norton's E P. I thereby unearth Norton's 'sustainability criterion' for his ideal procedure of deliberation. I then consider that this criterion seems to pose an inherent problem to EP. But, let us first examine why Norton commits to it and how the criterion is related to pragmatic decision-making.

'Sustainability' is, in its most common sense, a property of an action or of a system that can continue infinitely. This, of course, does not necessitate that something is only sustainable if it can be described as such in an environmental sense and will quite literally continue forever. For example, if a healthcare system is created in a way that ensures that it will surely not collapse in the coming centuries, it will likely be considered sustainable. And, if I spend twice as much money in a week as I earn, I am not exhibiting sustainable expenditure practices. This illustrates that sustainability can be applied in many different domains. Another key point is that 'infinite' obviously refers to time, although the temporal scale of sustainability is rarely specified. This relates to the question of the scope of sustainability: from when to when should we regard something to be sustainable? In the environmental debate, the scope of sustainability is often assumed to be as long as is conceivably possible or reasonable to assume on a planetary scale (Zia 2018).

Another, more pressing, point of sustainability regards the currency. The question here considers what should continue indefinitely - or for any other period of time - within a certain domain. Regarding the environment, two commonly accepted views of sustainability exist, which differ in currency: (a) weak sustainability and (b) strong sustainability. One often-cited paradigm that considers these views, and upon which Norton has reflected, comes from the economist Robert Solow. ${ }^{14}$ Solow assumes that various forms of capital (the currency) should be considered for future generations (1993). These forms of capital range from economic and ecological to human. Solow formulates capital in only broad, general terms, and so it is meant as an indication stating

14 Throughout his works Norton features and compares different paradigms of sustainability, such as in his 1995 paper 'Evaluating ecosystem states: Two competing paradigms'; his 2002 collected papers Searching for Sustainability; and the earlier mentioned Sustainability (2005). 
which resources are critical to the growth and prosperity of the community. ${ }^{15}$ The weak view of sustainability defines the concept of sustainability in terms of non-declining quantities of total capital. As long as the sum of capital is upheld, the system and actions of a community are sustainable. This also implies that different types of capital for future generations are thereby interchangeable. ${ }^{16}$ Moreover, as long as the sum is increasing, it does not matter if, for instance, natural capital is declining. This makes such a view very susceptible to 'total sum-criticism', which is often directed at utilitarianism: in such a weak sense, it seems justified, for instance, to diminish all natural capital as long as human capital is improved and thus the total sum increases (Driver 2014). Herman Daly has claimed, in contrast, that it is impossible to substitute natural capital with technology, knowledge or human capital (2006). Entire ecosystems, including our weather patterns, clean air and clean water, are simply indispensable. And, therefore, humanity should necessarily protect all (processes of) ecosystems. This claim that natural capital should always be maintained and thus even the smallest infringement should be avoided - is dubbed the strong view of sustainability.

Norton questions both of these views. Firstly, he addresses the vulnerability of ecosystems to which our actions can have radical and unknown consequences. The relationships between components in an ecosystem are so complex that we should not take any risks with them (Norton 2005, 353). ${ }^{17}$ This is not done due to either an anthropocentric or non-anthropocentric view. Rather, it is the uncertainty of the consequences of the ecosystem that he considers. This leads to the rejection of weak sustainability. However, as Norton sees it, strong sustainability misses the point by only focussing on always saving natural capital. Norton claims, and I believe rightly so, that many middle positions are conceivable between weak and strong sustainability. This includes possibilities that are eventually better for ecosystems but demand a preliminary consumption of natural capital. For example, by focussing on technological advancements, it might become possible to develop a mechanism that eventually cleans the air, even if that technology requires an expenditure

15 'Growth' and 'prosperity' are here not clear-defined terms, but by charitable interpretation, we should understand them as 'developing all aspects of society'.

16 The weak notion of sustainability is often seen as the economic 'sustainable development' ideal, expressed in the famous United Nations' Brundtland Report, and the subsequent developed paradigm used today by the United Nations and by countries worldwide, called the 'Sustainable Development Goals' (Brundtland et al. 1987; Griggs et al. 2013).

17 He claims this on the basis of 'ecological hierarchy theory', which is a particular description of the complexity of arrangements of biological organisms in relation to one and another (O'Neill et al. 1986). 
of natural resources. However, the question of course then arises as to which, or how much, natural capital should then be sustained. Everything with clean air? Entire ecosystems? These questions have become even more pressing for Norton since the publication of his latest book, in which he explicitly argues for such a middle-ground position (2015). Here, Norton claims that preserving some forms of natural capital is an unconditional necessity (Callicott 2018). But again, to what extent? And when are we permitted to sacrifice some natural capital for other capital?

\section{7}

\section{Norton's Sustainability}

To answer the preceding questions, let us first examine Norton's specific notion of sustainability in further depth. Interestingly enough, Norton bases his argument on a different type of currency. According to Norton, we should not be discussing (natural) capital and subsequently quantifying how much should be preserved. Instead, Norton argues, the community should argue from the currency of opportunities. And so, Norton defines sustainability as follows: 'A set of behaviors is understood as sustainable if and only if its practice in generation $m$ will not reduce the ratio of opportunities to constraints that will be encountered by individuals in generations n, o, p...' (2009, 41). Now, how does this relate to natural capital? Norton responds that the openness of opportunities means that natural capital should not be depleted, because we hold the duty to ensure that next generations have equal opportunities with natural capital as well. 'Opportunities' are, in this case, regarded as the possibility to do something with natural capital. But, would that not mean that we hold the same obligation regarding other forms of capital? Or, does natural capital hold some superior position?

According to Norton, it does. In explaining why, Norton explicitly refers to Aldo Leopold (Meine 2018, 287). Leopold, - a forerunner of environmental ethics - claimed in the 1940s that we ought to 'think like a mountain' (1949). By this concept, Leopold, followed here by Norton, meant that we should be aware that we as human beings, and as communities, are embedded in our natural environment. Natural capital is therefore not just something we can treat as if it were just another component of the world around us. No, natural capital is the world around us - and therefore, it is the community. For this reason, Norton claims that values that are attributed to natural capital, or our environment, are so-called 'place/based values' (2005, 336). He also refers to these as the 'constitutive values'. They 'constitute the community by giving it unity across generations; they are all tied up with the community's sense 
of itself and its members' sense of themselves as individual members of that community; they give meaning to the life of individuals and the community' $(2005,388)$. Therefore, the community must consider the temporal and spatial scale of the environment for any decision regarding the environment - think like the mountain.

It is here that it becomes most clear why Norton is dubbed by many scholars as a weak anthropocentrist. The community, which is constituted by human beings, is the centre of assessment, but because that community is embedded in the natural world, the natural worlds too needs be considered (1999b). Norton argues that if we were to expand our horizon on such a scale, it would not matter from a hardcore anthropocentric view: in the long run, a human being would want to defend non-human nature and ecosystems because they are all part of the same community. This is because, Norton assumes, any community will want to thrive and survive and thus maintain their constitutive (i.e. sustainable) values:

'If constitutive values of a place are threatened, a community member would fear for the special identity of his or her home place. Such fears might be expressed as "If that were to happen - if my community were to change in that way - I wouldn't even care to live here anymore". This outcome occurs when a place loses its "integrity", and the constitutive link between a community, its environment, and its values is (at least figuratively), severed. [...] Our purpose is to ensure that communities can, if they choose to be proactive, articulate policies that maintain a commitment to local natural and cultural history' $(2001,496)$.

Returning to the question I just raised, how can we determine to what extent we can infringe upon natural capital? According to Norton, we should, at the very least, approach this question with an eye to the larger ecosystem and deep values that constitute the community. As Paul Hirsch, a student of Norton, states, 'Metaphorically speaking [...] appropriate spatial and temporal scale from which to evaluate future decisions [...] is the scale of the Mountain' (2018, 90). Sustainability thereby maintains opportunities for our future community. And, as a community is defined by its constitutive - environmental - values, a sustainable decision is one made in light of the environment.

But now, we have still not yet explicitly answered the just-raised question: how can we then determine the best possible policy, while also considering these constitutive values? This occurs through the aforementioned deliberation. With continuous inquiry, and in rational dialogues, any community can simply decide what to do with natural capital, provided that it considers the 
above-mentioned notion. If this deliberation is not applied, the community would eventually (on the temporal/spatial scale) diminish itself. And, I have just explained that Norton assumes that any rational community would not want that. It thus follows that only sustainable policy - aimed at maintaining opportunities regarding natural capital - is the right policy.

It now seems fair to raise the following question: is it indeed the case that rational deliberation and open-ended inquiry necessarily lead to such an awareness of spatial and temporal values? Norton's preliminary conclusion does not seem to align with many empirical instances of rational discourses. A prime example is the US, a country that is run - at the time of this writing by climate sceptics. Argument on the basis of such rationale have been raised by Thompson, Hirsch and Callicott (2018; 2018; 2018). A first line of Norton's defence would be that such societies do not possess an ideal deliberation procedure, due to a failing discourse. ${ }^{18}$ Yet, such an argument does not hold. This is because Norton notes that in such societies, as long as continuous inquiry into better possibilities occurs, these possibilities will materialise (2005, chapter 3). But, the amelioration of deliberation is not self-emerging. Norton bites the bullet here. He acknowledges that the awareness of sustainability must come from somewhere.

And, Norton is, in fact, quite explicit in this $(2015,293)$. Because it is not self-evident that the sustainability principle emerges out of EP, Norton derives a principle from his notion of 'normative sustainability', which states that in order to facilitate sustainable change, the community 'requires a public discourse and the emergence of a "public" that can identify key values that must be sustained if the public interest is to be sustained. ${ }^{19}$ Key values should be understood here as the constitutive, environmental values, the public interest

18 For instance, special interests could be echoed in the debate, which undermines the discourse principle (Keulartz 2018, 204). Also see the Matthew Festenstein's critique on Deweyian pragmatism: "[Deweyian pragmatism] is vulnerable to appropriation by whatever social forces are most powerful” (2008, 90).

19 In Section 1 I pointed out that the epistemological principles are derived from two procedural heuristics. The sustainability principle is derived from Norton's third 'normative sustainability heuristic'. The fourth and final heuristic, is called the 'scales and boundaries' heuristic, which is reflected back in our awareness of natural capital, and constitutive values $(2005,293)$. I am aware that 'heuristic' is defined as a method with an open outcome. But by bringing in normative sustainability, Norton also implies the actual outcome. It invariably consists of a certain aim: the aim of a sustainable outcome of that deliberation. 
being, of course, at the very least, survival in the long run. In more practical terms, Norton means, as Hirsch points out, that policymakers should be aware of the constitutive values and subsequently hold a sustainable aim (2018, 91-93). This notion is rather revealing. It implies that Norton's procedural ideal is only met if decisions are made by a public that is aware of the environmental values, or, at least, if the procedure for considering these decisions is conditioned by this criterion. Normative sustainability touches, as Hirsch has made clear, 'the heart of a possible limitation as to what we can hope for from deliberation' (2018, 91). In other words, as long as deliberation does not meet this principle, it is not ideal - and therefore, it is not righteous. From this, it follows that we can bring forth EP s 'sustainability principle': deliberation is only ideal if the aim of that deliberation is sustainable.

It is here that a problem arises for Norton. Considering what Norton has brought forward thus far, it becomes clear that he makes two primary commitments in his EP regarding an ideal procedure for determining what is right policy. To make justified warranted assertions, the community should stick to the discourse principle in deliberating on as many possible values and opinions as possible. Hence, EP must accommodate value pluralism. But now, EP commits to an additional commitment, namely that of sustainability. And, this seems to be a specific value. Are these commitments compatible?

At first glance, this appears not to be the case. In the introduction, I have named this EP s prima facie problem. The problem could be constructed as follows: In the introduction and first chapter, I have elaborated on the notion that Norton regards his EP as an ideal for procedural decision-making. Norton does so based on the often-made distinction between procedural and substantive claims in political philosophy (Forstenzer 2011; Cohen 1997). ${ }^{20}$ Substantive claims seek to promote a specific description of a proposition. In political philosophy this adheres to, for example, democratic theory. Here, a substantive theory advocates a particular democratic condition for human flourishing (Christiano 2006). In other words, democracy becomes intrinsically valuable because it is an end in itself: it is democracy that is the good life in itself. Procedural claims only feature prescriptions of certain processes, for instance, the methodology regarding how a democracy should be constructed. Such a procedural account does not imply that the proposition is an end in itself, but rather that it is an instrument to reach an unspecified conception of the good life and thereby does not entail any specific notion of a certain goal.

20 More specifically, Norton takes Herbert Simon into consideration regarding this distinction (2015). 
Norton avoids making substantive claims, because that would necessitate also adhering to a specific end-in-itself conception of the good life and therefore embracing a specific value for how to live. This is precisely what he wishes to avoid, for obvious reasons: his ideal deliberation must consider the most possible values to determine the right policy. If Norton were to make a substantive claim, that is, to state which values should be considered, he would contradict his own ideal procedure. Instead, Norton opts for an openness of values allowing reasonable people to deliberate upon them. And, of course, this aligns with his earlier claims: they have all supported his ideal procedure of deliberation.

Nonetheless, the sustainability principle allegedly holds a certain aim, that is, to 'perpetuate place-based [environmental] values and project them into the future' (Norton 2005, 336). It therefore holds an ambition to reconstruct society in a certain direction - towards sustainability. One can argue that the sustainability principle is thereby a substantive claim. It is here that EP differs from pragmatism as simply an epistemological doctrine that only promotes reason. And so, EP cannot be an appropriate, reasonable social ideal - because reasonable people could disagree on its core philosophical commitment of sustainability (that EP claims is necessary for human flourishing). That it, reasonable people could possess good reasons to support other than sustainable values. This implies that $\mathrm{EP}$ is self-contradicting.

I am not the first one to notice this problem. Clark Wolf also argues that Norton's EP seems to imply a substantive goal (2018, §4.3). He further states that this would mean that the goal can be reached by shaping environmental practices around the instrumental achievement of that goal. He illustrates this by stating that a society could, for example, 'define a way to optimize the ratio of opportunities and constraints left as a bequest for future generations, subject to constraints imposed by budget, resource availability, and protections for later generations' $(2018,53)$. However, he then claims that considering sustainability as a goal would be at odds with Norton's theory, because Norton's project embraces

'an adaptionist model that takes goals (...) and constraints to be provisional. Adaptive management [i.e. Norton's ideal for decision-making] involves incremental decision-making and continued revision of goals in light of new information that becomes available' $(2018,53)$

Here, Wolf indeed states that Norton's ideal is actually procedural. But, he subsequently fails to provide any arguments as to why this is exactly so other than simply stating that Norton needs his project to be procedural. Callicott also addresses 
the problem but concludes only that Norton is not sufficiently adequate or robust in his notion of sustainability (2018). The primary reason behind Callicott's argument echoes my earlier criticism: Norton claims that sustainability is not a description of a society, but in all of his principles, he brings sustainability forward as if it were an aim for society to reach - which makes it a description.

One counterargument should now be brought forward: to pose the sustainability principle as a warranted assertion in itself. Just like the discourse principle and continuous inquiry should not be regarded as foundations, but as assertions in themselves, we could say the same for sustainability. What if we simply assume that sustainability should be considered because it has always turned out to be the best possible condition for decision-making? In this argument, the sustainability criterion is then an aim for environmental pragmatic decision-making, because we assert it that way. We then say that, just like the community that has embraced the method of inquiry and the discourse principle as the ideal of deliberation to come to knowing what is right, the community has also embraced sustainability as its aim. But, even if one assumes that sustainability is an assertion for a certain aim, it is still not clear if this makes EP viable, because why would Norton want to hold onto such an assertion if he must accommodate value pluralism in the first place? In each direction the argument is taken, it seems not possible for Norton to harmonize his procedural outset, and his necessary substantive aim.

\section{Conclusion}

Both in- and outside the academic world, a hot and heavy debate exists regarding the role of human beings in the non-human natural world. For many years, this issue was addressed on the basis of traditional, anthropocentric ethics. Since the emergence of the field of environmental ethics, a challenge has been posed to that traditional outlook: no longer should we reason from only intrinsic human values, but instead, we should attribute the non-human world with intrinsic value. Ultimately, this has led to a deadlock between those who favour policy based on intrinsic human values and those who support non-human intrinsic values. Under the great influence of classic American pragmatism, an alternative has been offered in this debate, environmental pragmatism referred to in this thesis as EP.

I have claimed that within EP a fundamental incompatibility exists between its pragmatic epistemological commitments and its commitment to sustainability. Here, EP is regarded as the epistemological justification for righteous decision-making, which Bryan Norton, EPs most prominent scholar, calls 
'adaptive ecosystem management'. I have made my claim on the basis of two steps. Firstly, I have considered how EP justifies its epistemological claims. After all, to make the right decision, we must first be able to know what is right. It is here that EP builds on the epistemological assumptions of classic pragmatism. Accordingly, a community - that is, a group of people holding the same constitutive values - is able, by means of ideal democratic deliberation, to arrive at warranted assertions of truth. This ideal is constituted out of what I have dubbed EP s epistemological principles: the principle of open-ended inquiry and the discourse principle. For a community to formulate a warranted assertion, it should therefore accommodate reasonable value pluralism.

Secondly, I have considered how Norton wishes to use this epistemic methodology to arrive at righteous decisions in environmental issues, as this is what EP aims to do. It is here that Norton commits to a third principle: sustainability. This principle states that any opportunity, or more specifically, those opportunities involving natural capital (i.e. the environment of the community), should be left open. As Norton argues his point, he makes it clear that a community is based upon its constitutive values, which are encapsulated in natural capital. Because no community wishes to diminish its constitutive values and thereby itself, no community wishes to diminish natural capital. Here, Norton leaves it open to appropriate deliberation by the democratic community to determine what exactly is right, as long as the outcome of that deliberation is sustainable. Yet, this imposes a problem of incoherence to Norton: if appropriate deliberation can only succeed by accommodating reasonable pluralism, then there ought not to be a principle that pre-emptively promotes a certain conception of the good life (in terms of value) - that is, sustainability. If this is so, EP cannot accommodate reasonable pluralism and would thereby be nonviable on its own terms.

I would like to conclude by emphasizing that $\mathrm{E} P$ does offer a promising outlook on environmental issues because of its focus on the pragmatic outcomes of policy. But to do so, it must hold a viable and coherent foundation. And so it seems that the problem unearthed in this paper first needs to be addressed, before we are able to fully approve of EP as the basis for environmental policy. I thus do not reject Norton's thinking, I only point out that this is an issue to be resolved.

\section{Acknowledgements}

This article is a condensed transcript of my Masters thesis in Philosophy, written at the University of Leiden. In the original thesis I do make an attempt to resolve the central issue raised in this paper. The full version is available at the library of Leiden. 


\section{References}

Aikin, Scott F., and Robert B. Talisse. 2018. Pragmatism, Pluralism, and the Nature of Philosophy. New York, NY: Routledge.

Anderson, Elizabeth. 1998. "Pragmatism, Science, and Moral Inquiry" In In Face of the Facts: Moral Inquiry in American Scholarship, edited by Fox Richard Wightman and Westbrook Robert B., 10-39. Washington, D.C.: Cambridge: Cambridge University Press.

Bacon, Michael. 2012. Pragmatism: An Introduction. Cambridge, UK: Polity.

Bragg, Melvyn. 2005. "Pragmatism." In Our Time. BBC 4. https://www.bbc.co.uk/ programmes/pooskgf5.

Brister, Evelyn. 2018. "Proceduralism and Expertise in Local Environmental DecisionMaking." In A Sustainable Philosophy - The Work of Bryan Norton, edited by Sarkar Sahotra and Minteer Ben A., 151-65. Cham: Springer International Publishing.

Brundtland, Gro Harlem, and World Commission on Environment and Development. 1987. Our Common Future. Oxford, UK: Oxford University Press.

Callicott, J. Baird. 2018. "Ecological Sustainability." In A Sustainable Philosophy-The Work of Bryan Norton, edited by Sarkar Sahotra and Minteer Ben A., 27-47. Cham: Springer International Publishing.

Christiano, Tom. 2006. "Democracy." In The Stanford Encyclopedia of Philosophy, edited by Zalta Edward N.. Stanford, CA: Metaphysics Research Lab, Stanford University.

Cohen, Joshua. 1997. "Procedure and Substance in Deliberative Democracy." In Deliberative Democracy: Essays on Reason and Politics, edited by Bohman James and Rehg William, 407-438. Boston, MA; London: The MIT Press.

Daley, Herman E. 2006. "Sustainable Development-Definitions, Principles, Policies." In The Future of Sustainability, edited by Keiner Marco, 39-53. Dordrecht: Springer Netherlands.

Dewey, John. 1938. Logic: The Theory of Inquiry. New York, NY: Henry Holt.

Dewey, John. 1941. "Propositions, Warranted Assertibility, and Truth." The Journal of Philosophy 38 (7): 169-86.

Dewey, John, and R. W. Sleeper. 1988. John Dewey: The Later Works, 1925-1953: 1939-1941/ Essays, Reviews, and Miscellany, Vol. 14. Edited by Boydston Jo Ann. 1st edition. Carbondale: Southern Illinois University Press.

Driver, Julia. 2014. "The History of Utilitarianism." In The Stanford Encyclopedia of Philosophy, edited by Zalta Edward N.. Stanford, CA: Metaphysics Research Lab, Stanford University.

Festenstein, Matthew. 2008. "John Dewey: Inquiry, Ethics, and Democracy." In The Oxford Handbook of American Philosophy, edited by Misak C. J.. Oxford: Oxford University Press. 
Forstenzer, Joshua. 2011. "A Pragmatist Philosophy of Democracy." Journal of Moral Philosophy 8 (1): 161-64.

Griggs, David, Mark Stafford-Smith, Owen Gaffney, Johan Rockström, Marcus C. Öhman, Priya Shyamsundar, Will Steffen, Gisbert Glaser, Norichika Kanie, and Ian Noble. 2013. "Sustainable Development Goals for People and Planet: Policy." Nature 495 (7441): 305-7.

Haack, Susan. 2004. "Pragmatism, Old and New." Contemporary Pragmatism 1 (1):3-41. Habermas, Jürgen. 1998. The inclusion of the other: Studies in political theory. Cambridge, MA: MIT Press.

Hirsch, Paul D. 2018. "Sustainable Change in a Fractured World." In A Sustainable Philosophy - The Work of Bryan Norton, edited by Sarkar Sahotra and Minteer Ben A., 87-97. Cham: Springer International Publishing.

Keulartz, Jozef. 2018. "Does Deliberation Promote Ecological Citizenship? The Convergence Hypothesis and the Reality of Polarization." In A Sustainable Philosophy - The Work of Bryan Norton, edited by Sarkar Sahotra and Minteer Ben A., 189-212. Cham: Springer International Publishing.

Leopold, Aldo. 1949. A Sand County Almanac. Reprint edition. New York: Ballantine Books.

Light, Andrew, and Eric Katz. 1996. Environmental Pragmatism. London: Psychology Press.

Meine, Curt. 2018. "The Pragmatist's View: A Conversation with Bryan Norton." In $A$ Sustainable Philosophy-The Work of Bryan Norton, edited by Sarkar Sahotra and Minteer Ben A., 273-92. Cham: Springer International Publishing.

Minteer, Ben. 2008. "Pragmatism, Piety, and Environmental Ethics." Worldviews: Global Religions, Culture, and Ecology 12 (2-3): 179-96.

Minteer, Ben. 2011. Refounding Environmental Ethics: Pragmatism, Principle, and Practice. Philadelphia: Temple University Press.

Minteer, Ben. 2017. "Environmental Ethics, Sustainability Science, and the Recovery of Pragmatism." The Oxford Handbook of Environmental Ethics, edited by Gardiner Stephen M. and Thompson Allen, 528-540. Oxford: Oxford University Press.

Nesher, Dan. 2002. On Truth and the Representation of Reality: A Collection of Inquiries from a Pragmatist Point of View. Lanham, MD: University Press of America.

Norton, Bryan G. 1995. "Evaluating Ecosystem States: Two Competing Paradigms." Ecological Economics, 14 (2): 113-27.

Norton, Bryan G. 1999a. "Pragmatism, Adaptive Management, and Sustainability." Environmental Values 8 (4): 451-66.

Norton, Bryan G. 1999b. "Ecology and opportunity: Intergenerational equity and sustainable options." In Fairness and futurity, edited by Dobson Andrew, 118-150. New York, NY: Oxford University Press. 
Norton, Bryan G. 2002. Searching for Sustainability. Cambridge; New York, NY: Cambridge University Press.

Norton, Bryan G. 2005. Sustainability: A Philosophy of Adaptive Ecosystem Management. Chicago: University of Chicago Press.

Norton, Bryan G. 2007a. "The Past and Future of Environmental Ethics/Philosophy." Ethics \& the Environment 12 (2): 134-136.

Norton, Bryan G. 20og. "Ethics and sustainable development: An adaptive approach to environmental Choice." In Handbook of sustainable development, edited by Atkinson Giles, Tietenberg T., et al., 27- 44. Northhampton: Edward Elgar Publishers.

Norton, Bryan G. 2015. Sustainable Values, Sustainable Change: A Guide to Environmental Decision Making. Chicago: University of Chicago Press.

Norton, Bryan G., and Anne C. Steinemann. 2001. "Environmental Values and Adaptive Management." Environmental Values 10 (4): 473-506.

Norton, Bryan, and Ben Minteer. 2002. "From Environmental Ethics to Environmental Public Philosophy: Ethicists and Economists, 1973-Future." In The International Yearbook of Environmental and Resource Economics 2002/2003: A Survey of Current Issues, edited by Tietenberg Thomas H. and Folmer Henk, 373-407. Cheltenham: Edward Elgar Pub.

Odenbaugh, Jay. 2012. "Reconstruction in Environmental Philosophy." BioScience 62 (8): 769-70.

O’Neill, Robert V., Donald Lee Deangelis, J. B. Waide, Timothy F. H. Allen, and Garland E. Allen. 1986. A Hierarchical Concept of Ecosystems. Princeton, NJ: Princeton University Press.

Peirce, Charles S. 1955. Philosophical Writings of Peirce. Edited by Buchler Justus. New York, NY: Dover Publications.

Putnam, Hilary. 1995. Pragmatism: An Open Question. Blackwell.

Putnam, Hilary, and James Conant. 1994. Words and Life. Cambridge, MA: Harvard University Press.

Putnam, Hilary and Ruth Anna Putnam. 2017. Pragmatism as a Way of Life: The Lasting Legacy of William James and John Dewey. Edited by Macarthur David. Cambridge, MA: The Belknap Press of Harvard University Press.

Rawls, John. 2005. Political Liberalism. New York, NY: Columbia University Press.

Samuelsson, Lars. 2010. "Environmental Pragmatism and Environmental Philosophy: A Bad Marriage!" Environmental Ethics: An Interdisciplinary Journal Dedicated to the Philosophical Aspects of Environmental Problems 32 (4): 405-15.

Sarkar, Sahotra, and Ben Minteer. 2018. A Sustainable Philosophy: The Work of Bryan Norton. Cham: Springer Berlin Heidelberg.

Solow, Robert. 1993. "An Almost Practical Step toward Sustainability." Resources Policy $19(3): 162-72$. 
Stephens, Piers H. G. 2012. "The Turn of the Skew: Pragmatism, Environmental Philosophy and the Ghost of William James." Contemporary Pragmatism 9 (1): 25-52. Stephens, Piers H. G. 2007. "Book Review Essay: Sustainability, Democracy, and Pragmatism Bryan Norton's Philosophy of Ecosystem Management." Organization \& Environment $20(3): 386-92$.

Thompson, Paul B. 2007. "Norton's 'Sustainability': Some Comments on Risk and Sustainability." Journal of Agricultural and Environmental Ethics 20 (4): 375-86.

Thompson, Paul B. 2018. "Norton and Sustainability as Such." In A Sustainable Philosophy - The Work of Bryan Norton, edited by Sarkar Sahotra and Minteer Ben A., 26:7-26. Cham: Springer International Publishing.

Tiercelin, Claudine. 2014. The Pragmatists and the Human Logic of Truth. Paris: Collège de France.

Vik, Anders Krosshavn. 2014. "Environmental Pragmatism, Systematism and the Reach of Environmental Ethics." MA Thesis Philosophy, Oslo: University of Oslo.

Weston, Anthony. 1985. "Beyond Intrinsic Value: Pragmatism in Environmental Ethics." Environmental Ethics 7 (4): 321-339.

Wolf, Clark. 2018. "Sustainability and the Currency of Intergenerational Obligations: Norton, Solow, Rawls, Mill, and Sen on Problems of Intergenerational Allocation." In A Sustainable Philosophy - The Work of Bryan Norton, edited by Sarkar Sahotra and Minteer Ben A., 49-70. Cham: Springer International Publishing.

Zia, Asim. 2018. "Adaptive Management in Social Ecological Systems: Taming the Wicked?" In A Sustainable Philosophy - The Work of Bryan Norton, edited by Sarkar Sahotra and Minteer Ben A., 167-87. Cham: Springer International Publishing. 